\title{
miR-34a derived from mesenchymal stem cells stimulates senescence in glioma cells by inducing DNA damage
}

\author{
QUN LI* ${ }^{*}$, CHENGDE WANG ${ }^{*}$, LIN CAI, JIANGLONG LU, ZHANGZHANG ZHU, \\ CHUNYONG WANG, ZHIPENG SU and XIANGHE LU
}

Department of Neurosurgery, First Affiliated Hospital, Wenzhou Medical University, Wenzhou, Zhejiang 325000, P.R. China

Received February 6, 2018; Accepted December 12, 2018

DOI: $10.3892 / \mathrm{mmr} .2018 .9800$

\begin{abstract}
Insights into the roles of microRNAs (miRNAs/miRs) in development and disease, particularly in cancer, have made miRNAs attractive tools and targets for novel therapeutic approaches in the treatment of glioma. miR-34a, as a well-known tumor suppressor miRNA, is closely related with cellular senescence. Mesenchymal stem cells (MSCs) are a major component of the tumor microenvironment and possess the ability to deliver exogenous miRs to glioma cells to exert anti-tumor effects. The present study investigated whether modified MSCs with miR-34a possess an anti-tumor function in glioma cells. A Transwell system was used to co-culture U87 glioma cells and MSCs overexpressing miR-34a, and cell proliferation and senescence assessed. The expression of senescence-related genes p53, Cdkn1a, and Cdkn2c were tested using reverse transcription-quantitative polymerase chain reaction and protein expression levels of sirtuin 1 (SIRT1) and $\gamma$-H2A histone family, member X were detected by western blotting. Telomerase activity of U87 cells was examined using the Telo TAGGG Telomerase PCR ELISA PLUS kit. The results demonstrated that the delivered exogenous miR-34a from MSCs significantly decreased expression of the target gene SIRT1. In addition, the delivered miR-34a decreased the proliferation of glioma cells and provoked the expression of senescence-related genes p53, Cdkn1a, and Cdkn2c. In addition, upregulation of miR-34a induced DNA damage, shortened telomere length and impaired telomerase activity. However, these pro-senescent effects were reversed by forced SIRT1 upregulation. In conclusion, the results
\end{abstract}

Correspondence to: Dr Zhipeng Su or Dr Xianghe Lu, Department of Neurosurgery, First Affiliated Hospital, Wenzhou Medical University, 2 Fuxue Lane, Wenzhou, Zhejiang 325000, P.R. China

E-mail: drsuzhipeng@163.com

E-mail:dr_luxh@sina.com

*Contributed equally

Key words: mesenchymal stem cell, glioma, senescence, microRNA-34a, sirtuin 1, DNA damage demonstrated a novel role for miR-34a, inducing glioma cell senescence, whereas miR-34a modulation of SIRT1, inducing DNA damage, is crucial for miRNA replacement therapy in glioma treatment.

\section{Introduction}

Glioma is the most common primary malignant tumor of the central nervous system in adults and is associated with an extremely poor prognosis (1). The standard treatment for glioma includes maximal safe surgical resection, followed by radiotherapy and chemotherapy with temozolomide (2). However, life-threatening tumor recurrences are inevitable in the vast majority of patients despite the best available treatments (3). The poor survival rate is mainly associated with the failure of therapeutic agent delivery to tumor regions (4). Therefore, the development of non-viral biotechnology that allows safe and effective gene and cell therapy in glioma is required. Human bone marrow-derived mesenchymal stem cells (hBM-MSCs) exhibit high anti-glioma tropism and represent a promising delivery vehicle for targeted brain tumor therapy $(4,5)$. The present study aimed to test whether modified hBM-MSCs can be used as delivery agents to improve brain tumor therapy.

MicroRNAs (miRNAs/miRs) are a class of non-coding RNA molecules that serve crucial functions in cell senescence, proliferation and survival by binding to target mRNAs, resulting in mRNA translational inhibition or degradation (6). Among the miRNAs dysregulated in cancer, the miR-34 family has received substantial attention. miR-34a, one of the best-studied members of the family, is reported to serve a part in p53-mediated senescence following DNA damage, exerting an anti-tumor effect (7). miR-34a is closely related with cellular senescence; in breast cancer cells, it inhibits proliferation and invasion, activates senescence and promotes sensitivity to chemotherapy (8). Recent studies have suggested that modified MSCs can deliver miRNAs to induce a therapeutic effect in glioma $(4,9)$. The present study explored whether hMSC-delivered miR-34a could induce a pro-senescent effect in glioma cells to mediate a therapeutic effect.

The preservation of genomic integrity is an essential process for cell homeostasis and defects in the DNA-damage response; a complex network of proteins required for cell-cycle 
checkpoint and DNA repair has been associated with tumorigenesis (10). Targeting the DNA damage checkpoint response in glioma cells has provided a therapeutic model for malignant brain cancers, accompanied with the ability to overcome radioresistance (11). miR-34a serves a part in p53-mediated senescence following DNA damage by directly targeting the anti-senescent protein sirtuin 1 (SIRT1) in the treatment of breast cancer (12).

The present study investigated whether hMSCs overexpressing miR-34a could deliver miR-34a to induce DNA damage and subsequently cause cellular senescence in glioma cells. Furthermore, it investigated the pro-senescent role of miR-34a delivered by hMSCs in glioma cells, and discussed the effect of the miR-34a/SIRT1 pathway inducing DNA damage in the glioma cells senescence process.

\section{Materials and methods}

Cell culture and transwell co-cultures of MSCs-U87. The hBM-MSCs were purchased from ATCC (Manassas, VA, USA), seeded at 5,000 cells $/ \mathrm{cm}^{2}$ in growth media [Dulbecco's modified Eagle's medium (DMEM; HyClone; GE Healthcare Life Sciences, Logan, UT, USA) supplemented with $10 \%$ fetal bovine serum (FBS; HyClone; GE Healthcare Life Sciences), 1\% Glutamax (Sigma-Aldrich; Merck KGaA, Darmstadt, Germany) and 1\% penicillin-streptomycin (Beyotime Institute of Biotechnology, Jiangsu, China)] and grown to $80-85 \%$ confluence.

The U87-MG glioblastoma of unknown origin cell line was purchased from ATCC and maintained in DMEM supplemented with $10 \%$ FBS and $1 \%$ penicillin-streptomycin. The cells were cultured under standard condition of $95 \%$ humidity and $5 \% \mathrm{CO}_{2}$ at $37^{\circ} \mathrm{C}$.

A Transwell system was used to prevent direct contact between hMSCs and the U87 cells. hMSCs and U87 cells were placed in the upper and lower layers of the Transwell plate, respectively, at a density of $1 \times 10^{6}$ cells/well.

Cell transfection. Prior to miR-34a mimic and negative control (NC) mimic transfection, hMSCs were seeded into 6-well plates at a density of $1 \times 10^{5}$ cells per well and incubated for $12 \mathrm{~h}$. For overexpression of miR-34a, cells were transfected with $100 \mathrm{nM}$ miR-34a mimic (5'-UGGCAGUGUCUUAGC UGGUUGUAACCAGCUAAGACACUGCCAUU-3') or NC mimic (5'-UGUCAGCUUUGGAGCUGGUUGUAACCU AAGAUGCCACCAGCAUU-3'; both Invitrogen; Thermo Fisher Scientific, Inc., Waltham, MA, USA). miR-34a mimic and NC mimic were transfected into hMSCs using a transfection reagent (X-treme Transfection Reagent; Roche Applied Science, Penzberg, Germany) according to the manufacturer's protocol. Then, $48 \mathrm{~h}$ following transfection, cells were harvested for further analysis. The transfection efficiency was analyzed by reverse transcription-quantitative polymerase chain reaction (RT-qPCR), using U6 as the internal reference gene.

Adenoviral vectors expressing SIRT1 (Ad-SIRT1) and control scrambled sequence (Ad-Ctrl) were designed and synthesized by Shanghai GeneChem Co., Ltd. (Shanghai, China). U87 cells were transfected using Lipofectamine $2000^{\circledR}$ (Invitrogen; Thermo Fisher Scientific, Inc.) at a final concentration of $100 \mathrm{nM}$. Subsequent experiments were performed $48 \mathrm{~h}$ after adenoviral transfection.

Cell proliferation assay. Cell proliferation was assessed using the Cell Counting Kit-8 assay (CCK-8) according to the manufacturer's protocol (HaiGene Technology, Harbin, China). Cells in DMEM supplemented with $10 \%$ FBS were seeded at $2 \times 10^{3}$ cells/well in 96-well plates and incubated at $37^{\circ} \mathrm{C}$ for 24,48 , and $72 \mathrm{~h}$. CCK-8 solution $(10 \mu \mathrm{l})$ was added to each well, and the plates were incubated for $1 \mathrm{~h}$ at $37^{\circ} \mathrm{C}$. The absorbance of cells at $450 \mathrm{~nm}$ [Optical Density (OD) 450] was measured.

$R T-q P C R$. The total RNA was isolated by TRIzol ${ }^{\circledR}$ reagent (Life Technologies; Thermo Fisher Scientific, Inc.), according to the manufacturer's protocol. The first-strand cDNA was synthesized through a cDNA synthesis kit (Invitrogen; Thermo Fisher Scientific, Inc.), according to the manufacturer's protocol. The qPCR was carried out using the FastStart Universal SYBR Master (Roche Diagnostics GmbH, Mannheim, Germany) and fluorescence quantitative PCR system. The thermocycling conditions were as follows: 40 cycles of $95^{\circ} \mathrm{C}$ for $15 \mathrm{sec}, 63^{\circ} \mathrm{C}$ for $20 \mathrm{sec}$ and $71^{\circ} \mathrm{C}$ for $25 \mathrm{sec}$. The experiments were repeated three times. Quantification was performed relative to the levels of the housekeeping gene GAPDH. The data analysis was performed using the $2^{-\Delta \Delta \mathrm{Cq}}$ method (13). The primer sequences are listed in the Table I.

Western blotting. Cells were lysed in ice-cold lysis buffer to obtain total protein (Beyotime Institute of Biotechnology). Protein concentrations were measured using a BCA Protein Assay kit (Beyotime Institute of Biotechnology). Equal amounts of total protein $(20 \mu \mathrm{g} /$ lane) were separated by $10 \%$ SDS-PAGE and transferred onto nitrocellulose membranes. Membranes were blocked with $5 \%$ nonfat dry milk at $37^{\circ} \mathrm{C}$ for $1 \mathrm{~h}$, and then incubated with primary antibodies against SIRT1 $(1: 1,000$; cat. no. 3931), $\gamma$-H2AX (1:500; cat. no. 9718) and $\beta$-actin (1:2,000; cat. no. 4970; all Cell Signaling Technology, Inc., Danvers, MA, USA) at $4^{\circ} \mathrm{C}$ overnight. Subsequently, the membranes were incubated with goat anti-rabbit immunoglobulin G, horseradish peroxidase-linked secondary antibody (1:2,000; cat. no. 7074; Cell Signaling Technology, Inc.) at $37^{\circ} \mathrm{C}$ for $1 \mathrm{~h}$. Proteins were detected using the BeyoECL Plus kit (Beyotime Institute of Biotechnology). The stained protein bands were visualized on a Bio-Rad ChemiDoc XRS equipment, and analyzed using Quantity One software version 4.5.2 (Bio-Rad Laboratories, Inc., Hercules, CA, USA).

Senescence-associated $\beta$-galactosidase (SA- $\beta$-gal) assay. Cellular senescence was measured using SA- $\beta$-gal assay (Cell Signaling Technology, Inc.). Briefly, the cells at the density of $2 \times 10^{4}$ were washed with PBS, fixed with $2 \%$ paraformaldehyde for $30 \mathrm{~min}$ at room temperature and incubated with a fresh SA- $\beta$-gal staining solution as previously described (14). The results are presented as a ratio of the SA- $\beta$-gal-positive cells to the total cells for at least 100 cells per treatment per experiment.

Relative telomere length measurement. Relative telomere length quantification in U87 cells was performed using qPCR 
Table I. Primer sequences.

\begin{tabular}{|c|c|}
\hline Genes & Sequences \\
\hline miR-34a & $\begin{array}{l}\text { F: 5'-CAGAGCATCACACGCAAGC-3' } \\
\text { R: 5'-CAGGAAACAGAAACCCCAGC-3' }\end{array}$ \\
\hline p53 & $\begin{array}{l}\text { F: 5'-TTCCTCTTCCTGCAGTACTC-3' } \\
\text { R: 5'-ACCCTGGGCAACCAGCCCTGT-3' }\end{array}$ \\
\hline Cdkn1a & $\begin{array}{l}\text { F: 5'-TCACTGTCTTGTACCCTTGTGC-3' } \\
\text { R: 5'-GGCGTTTGGAGTGGTAGAAA-3' }\end{array}$ \\
\hline Cdkn2c & $\begin{array}{l}\text { F: 5'-CGGGAGGTTCTTGTTCTG-3' } \\
\text { R: 5'-TTTGTTGGCTTGCTTGAC-3' }\end{array}$ \\
\hline SIRT1 & $\begin{array}{l}\text { F: 5'-TGGAGGAAGGGTGTTTGTCC-3' } \\
\text { R: 5'-CAAGGCAGATGGTGGCTGA-3' }\end{array}$ \\
\hline Telomere length & $\begin{array}{l}\text { F:5'-CGGTTTGTTTGGGTTTGGGTTTGGGTTTGGGTTTGGGTT-3' } \\
\text { R: 5'-GGCTTGCCTTACCCTTACCCTTACCCTTACCCTTACCCT-3' }\end{array}$ \\
\hline ERCC1 & $\begin{array}{l}\text { F: 5'-GGGAATTTGGCGACGTAATC-3' } \\
\text { R: 5'-GCGGAGGCTGAGGAACG-3' }\end{array}$ \\
\hline ERCC5 & $\begin{array}{l}\text { F: 5'-GAAGCAATGCCAGAGGAG-3' } \\
\text { R: 5'-CCACTCTCCTTGACTCTACC-3' }\end{array}$ \\
\hline GAPDH & $\begin{array}{l}\text { F: 5'-GGGTGGAGCCAAACGGGTC-3' } \\
\text { R: 5'-GGAGTTGCTGTTGAAGTCGCA-3' }\end{array}$ \\
\hline U6 & $\begin{array}{l}\text { F: 5'-AAGGCCACGGATAGGTCCATA-3' } \\
\text { R: 5'-CGCTTTGGTGGTTCTGAAAGG-3' }\end{array}$ \\
\hline
\end{tabular}

F, forward; R, reverse.

as previously described $(15,16)$, using GAPDH as the normalizing gene. The primer pairs used to detect the telomere length are listed in Table I.

Relative telomerase activity measurement. Telomerase activity of whole cell lysate was measured by a TeloTAGGG ${ }^{\mathrm{TM}}$ telomerase PCR ELISA PLUS kit (cat. no. 12013789001; Roche Diagnostics GmbH, Penzberg, Germany). Cell lysates were centrifuged at $12,000 \mathrm{x}$ g for $20 \mathrm{~min}$ at $4^{\circ} \mathrm{C}$ and $3 \mu \mathrm{l}$ of cell extract was used for each telomeric repeat PCR amplification reaction and $3 \mu \mathrm{l}$ of inactivated cell lysate were used for Telomeric Repeat Amplification Protocol (TRAP) reaction according to the manufacturer's recommendations. Using the ELISA method, the amplified products were immobilized on streptavidin-coated microtiter plates via biotin-streptavidin interaction. Thereafter, anti-digoxigenin horseradish peroxidase solution was added to detect the amplifications. Following addition of the peroxidase substrate (3,3',5,5'-tetramethylbenzidine), the amount of TRAP products was determined by measurement of absorbance at $450 \mathrm{~nm}$ using a microplate reader.

Statistical analysis. Data were expressed as the mean \pm standard deviation. Differences among three groups or more were tested by one-way analysis of variance followed by Tukey's post hoc test, and comparisons between two groups were evaluated by Student's t-tests using SPSS version 19.0 (IBM Corp., Armonk, NY, USA). P<0.05 was considered to indicate a statistically significant difference.

\section{Results}

Introduction of cellular senescence in glioma cells following co-culture with hMSCs overexpressing miR-34a. As a well-known tumor suppressor miRNA, miR-34 is closely associated with cellular senescence (17). The present study further examined whether delivery of miR-34a by hMSCs can induce cellular senescence in U87 glioma cells. As presented in Fig. 1A, when hMSCs were transfected with miR-34a mimic, the expression of miR-34a significantly increased. Next, a Transwell culture system was used: Co-culturing with MSCs overexpressing miR-34a for $24 \mathrm{~h}$ impaired U87 glioma cell proliferation (Fig. 1B). Additionally, it induced expression of senescence-associated genes p53 (Fig. 1C), Cdknla (Fig. 1D) and Cdkn2c (Fig. 1E). As expected, this result was corroborated by an increase in the percentage of cells positively marked with the senescence-associated $\beta$-galactosidase (Fig. 1F and G).

Downregulation of SIRT1 expression in glioma cells by $h M S C$-derived miR-34a. To detect the delivery of miR-34a to U87 glioma cells, the expression of miR-34a in the U87 glioma cells was examined. As shown in Fig. 2A, intracellular miR-34a expression in U87 glioma cells increased when co-cultured with hMSCs overexpressing miR-34a. However, the coculture of U87 cells with hMSCs transfected with NC mimic did not induce miR-34a expression.

As a well-known target of miR-34a, SIRT1 was selected for further study. To ensure that miR-34a downregulates 


\section{A}

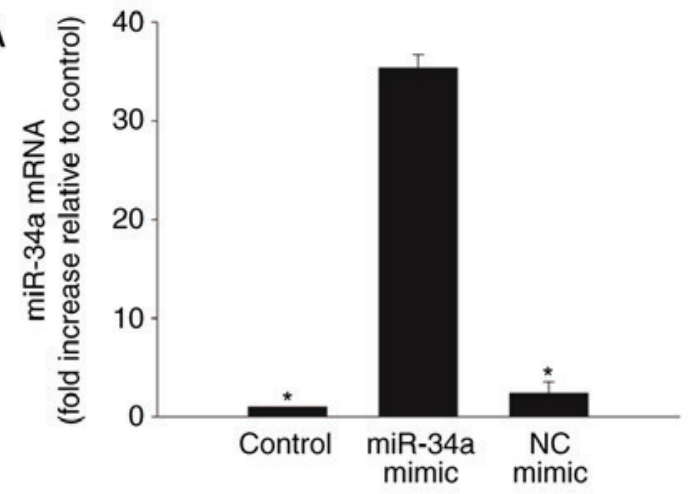

C

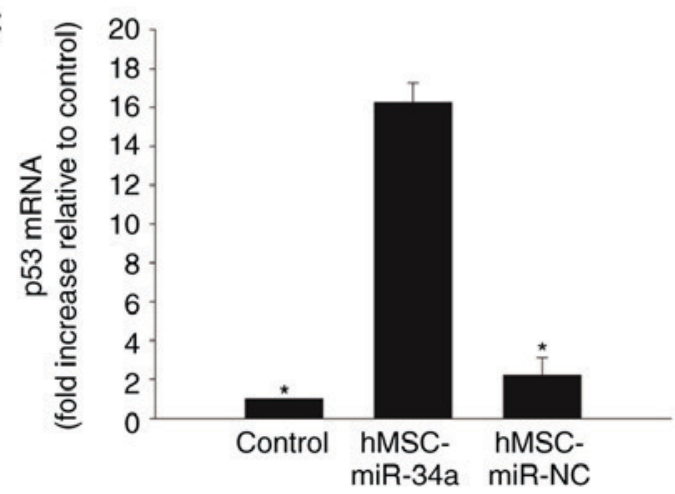

$\mathrm{E}$

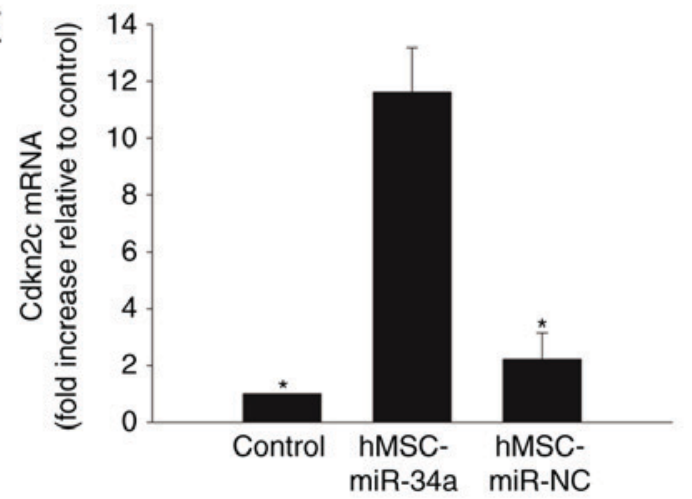

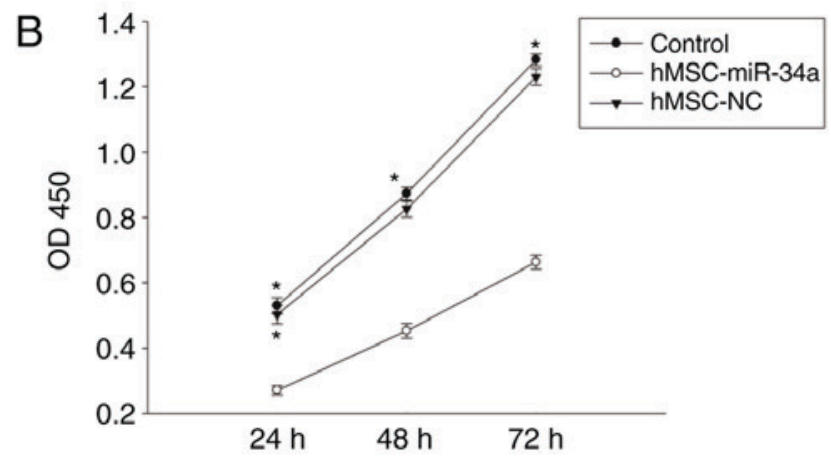
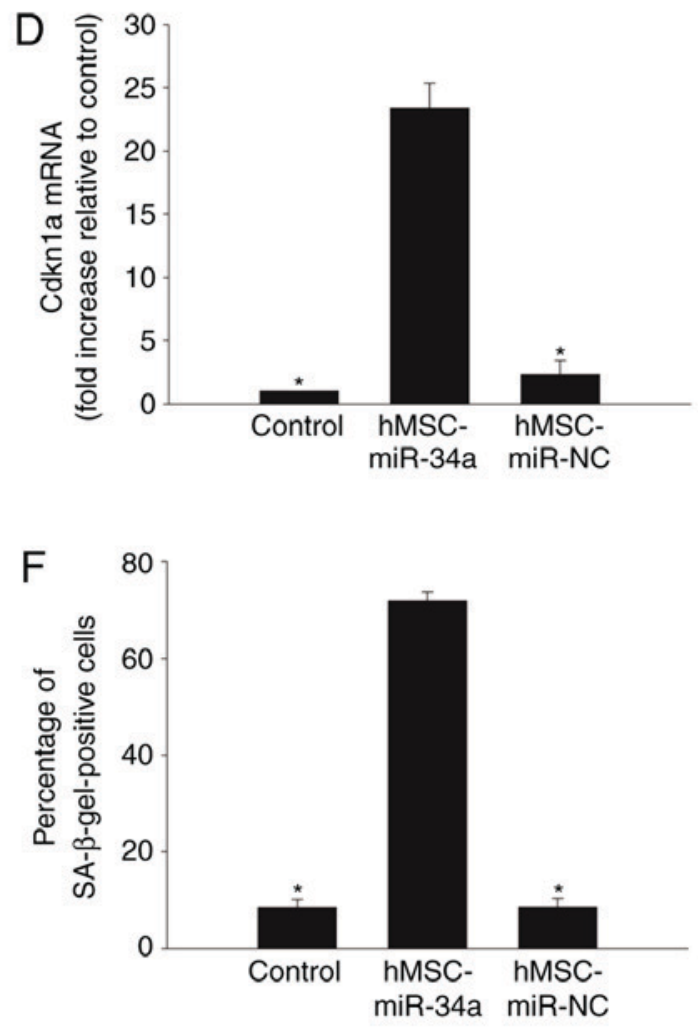

G

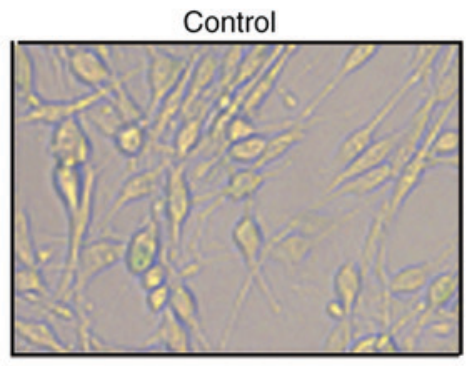

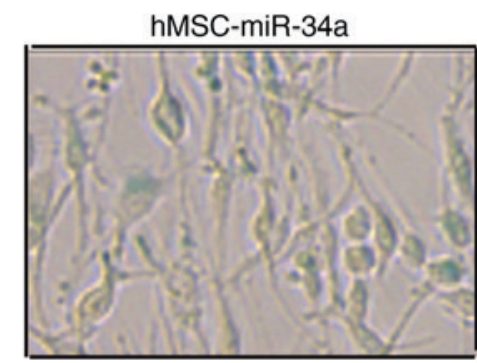

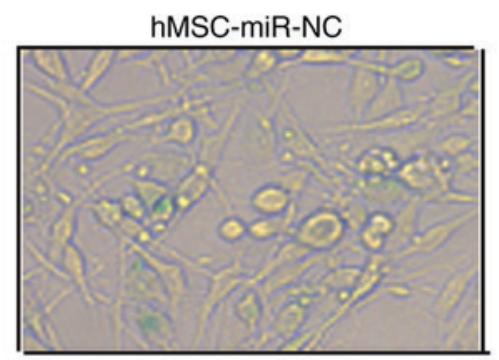

Figure 1. Introduction of cellular senescence in glioma cells following co-culturing with hMSCs overexpressing miR-34a. (A) RT-qPCR analysis of miR-34a mRNA levels in hMSCs, hMSCs transfected with miR-34a mimic, or NC mimic. " $\mathrm{P}<0.05$ vs. miR-34a mimic. To explore the role of the pro-senescence effect of hMSCs overexpressing miR-34a on U87 cells, we used a Transwell co-culture system. In the U87 cells co-cultured with hMSCs overexpressing miR-34a, or with hMSCs transfected NC mimic $24 \mathrm{~h}$, (B) cell proliferation was determined by CCK-8 assay and (C) p53, (D) Cdkn1a, and (E) Cdkn2c mRNA levels were analyzed by RT-qPCR. (F) The percentage of $\beta$-gal-positive cells. (G) Representative images of the SA- $\beta$-gal staining (magnification, $x 40$ ). Data represents the mean \pm standard deviation from three independent experiments; " $\mathrm{P}<0.05$ vs. hMSC-miR-34a. hMSCs, human mesenchymal stem cells; miR, microRNAs; NC, negative control; $\beta$-gal, $\beta$-galactosidase; SA, senescence-associated; RT-qPCR, reverse transcription-quantitative polymerase chain reaction.

SIRT1 in U87 cells, its expression was detected with western blot analysis in U87 cells. The results confirmed that the level of SIRT1 decreased in U87 cells co-cultured with hMSCs overexpressing miR-34a, while NC mimic transfection had no observable effect (Fig. 2B and C).
Modulation of SIRT1 weakens pro-senescent effect of miR-34a derived from hMSCs. To further detect the miR-34a/SIRT1 signaling pathway in the induction of U87 cellular senescence, SIRT1 was overexpressed using Ad-SIRT1 transfection. As shown in Fig. 3A, Ad-SIRT1 

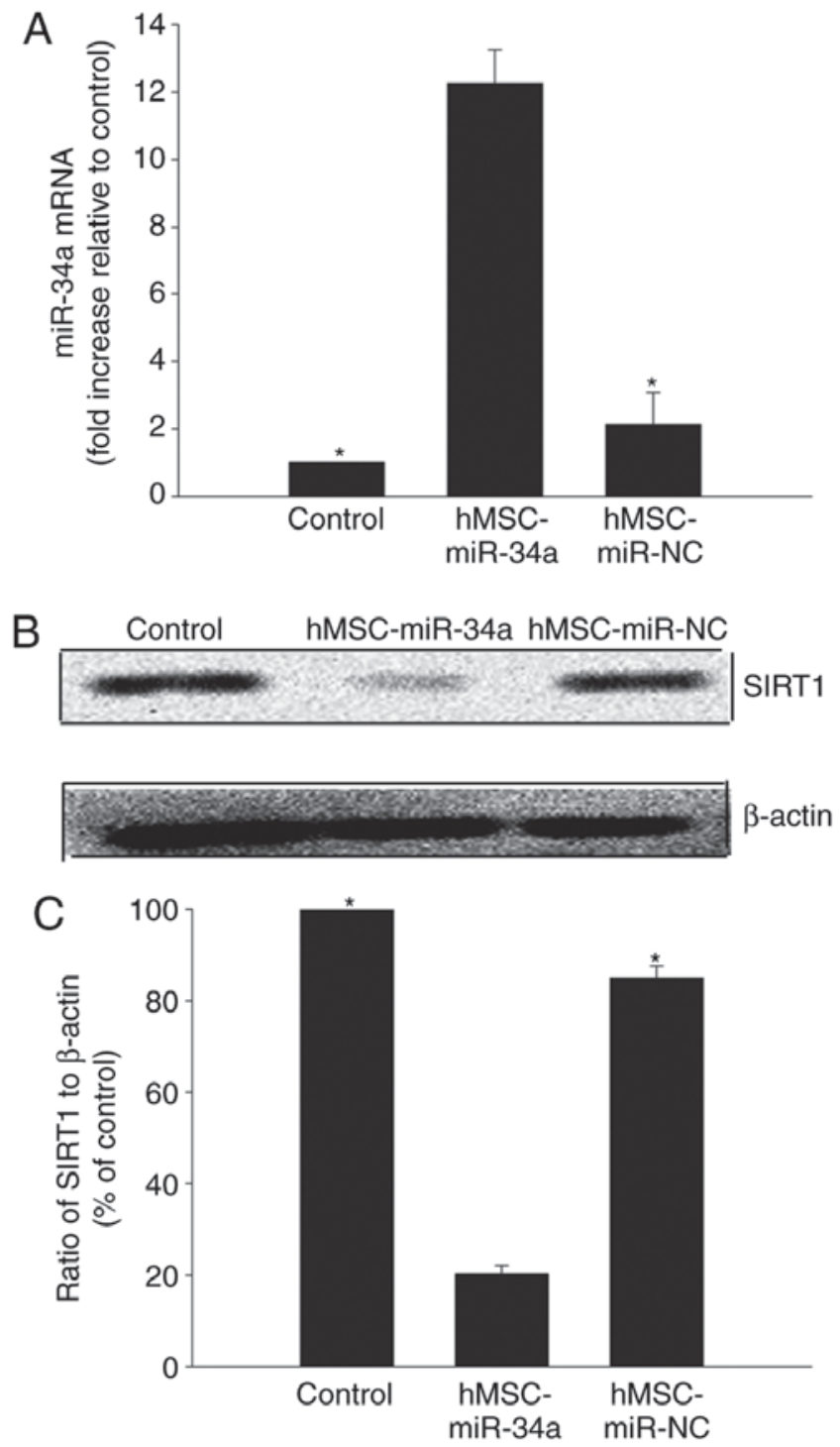

Figure 2. Downregulation SIRT1 expression in glioma cells by hMSC-derived miR-34a. (A) Reverse transcription-quantitative polymerase chain reaction analysis of miR-34a mRNA levels in U87 cells, U87 cells co-cultured with hMSCs transfected with miR-34a mimic, or NC mimic. (B) Image and (C) quantification of western blotting of SIRT1 protein expression levels in U87 cells, U87 cells co-culturing with hMSCs overexpressing miR-34a, or hMSCs transfected with miR-NC mimic. Data represent mean \pm standard deviation from three independent experiments; ${ }^{*} \mathrm{P}<0.05$ vs. hMSC-miR-34a. hMSCs, human mesenchymal stem cells; miR, microRNAs; NC, negative control; SIRT1, sirtuin 1 .

transfection induced high SIRT1 expression in the U87 cells, compared with the control group.

The results revealed that U87 cells, transfected with Ad-SIRT1, recovered cellular proliferation (Fig. 3B), decreased senescent related gene p53 expression (Fig. 3C), as well as the expression of cell cycle inhibitors Cdkn1a (Fig. 3D) and $\mathrm{Cdkn} 2 \mathrm{c}$ (Fig. 3E). It also decreased senescence-associated $\beta$-galactosidase positive cells (Fig. 3F and G).

hMSC-derived miR-34a trigger the DNA-damage response and impair telomeres. DNA damage and telomere dysfunction leads to cellular senescence, particularly in tumors (18). Immunoblotting was used to detect DNA damage-related protein $\gamma-\mathrm{H}_{2} \mathrm{AX}$ expression. Following co-culturing with
hMSCs overexpressing miR-34a, $\gamma-\mathrm{H}_{2} \mathrm{AX}$ expression in U87 cells was increased (Fig. 4A and B) while DNA repair related genes ERCC1 and ERCC5 were decreased (Fig. 4C and D). In addition, it was identified that co-culture with hMSCs overexpressing miR-34a decreased the telomere length and impaired the telomerase activity (Fig. 4E and F). However, SIRT1 overexpression in the U87 cells rebalanced the DNA-damage and repair, lengthened the telomere length and recovered the telomerase activity, but Ad-Ctrl did not (Fig. 4).

\section{Discussion}

Gliomas are primary brain tumors derived from the malignant transformation of oligodendrocytes and astrocytes (19). Gliomas typically exhibit a poor prognosis irrespective of treatment, with the most common form, glioblastoma multiforme (GBM), with a 5-year survival rate of only 5\% (20). Current treatment regimens for GBM include surgery, radiation therapy and chemotherapy (21). Unfortunately, due to the diffuse nature of malignant gliomas, complete surgical resection is almost impossible. In addition, due to their resistance to chemotherapy and radiotherapy, the post-surgical treatment of GBM also requires improvement (22). One of the reasons for the poor survival rate is the tumor microenvironment, which is not only hypoxic and acidic but also is surrounded by high interstitial pressure, which acts as a pathologic barrier to drug delivery into tumors (23). One efficient method of targeted delivery to glioma is the use of adult stem cells as a delivery agent that can carry a therapeutic agent (24), with hMSCs among the most attractive candidates for cell-based therapy. hMSCs can cross the blood-brain barrier and have been shown to possess innate tumor tropism and low immunogenicity (25). The present study identified that hMSCs overexpressing miR-34a delivered the miR to glioma cells.

In just over two decades since the discovery of the first miRNA, the field of miRNA biology has been considerably explored. Insights into the roles of miRNAs in development of diseases, particularly in cancers, have made miRNAs attractive tools and targets for novel therapeutic approaches (17). Several studies have demonstrated that loss of miR-34a has a causative role in lung, breast and several other cancers $(12,26)$. Acute miR-34 overexpression elicits various p53 downstream effects, including cell cycle arrest, apoptosis, and senescence $(27,28)$. This was consistent with the results of the present study, which identified that MSCs overexpressing miR-34a delivered miR-34a to the U87 cells, resulting in lower cell proliferation, increased p53 expression, depression of the cell cycle and induction of cellular senescence.

One of the important factors involved in miR-34a inhibition is SIRT1 in the glioma (29); miR-34a indirectly promotes cellular senescence by targeting and repressing levels of SIRT1 (30). A previous study revealed that SIRT1 is an effective anti-senescent factor, and serves protective roles in several neurodegenerative diseases (31). In glioma, inhibition of Sirt1 expression induces sensitization to radiotherapy (32). The results of the present study suggested that miR-34a derived from MSCs inhibited the expression of SIRT1 in the U87 cells. To further confirm the role of SIRT1 in the senescence of glioma cells, Ad-SIRT1 transfection was use to 

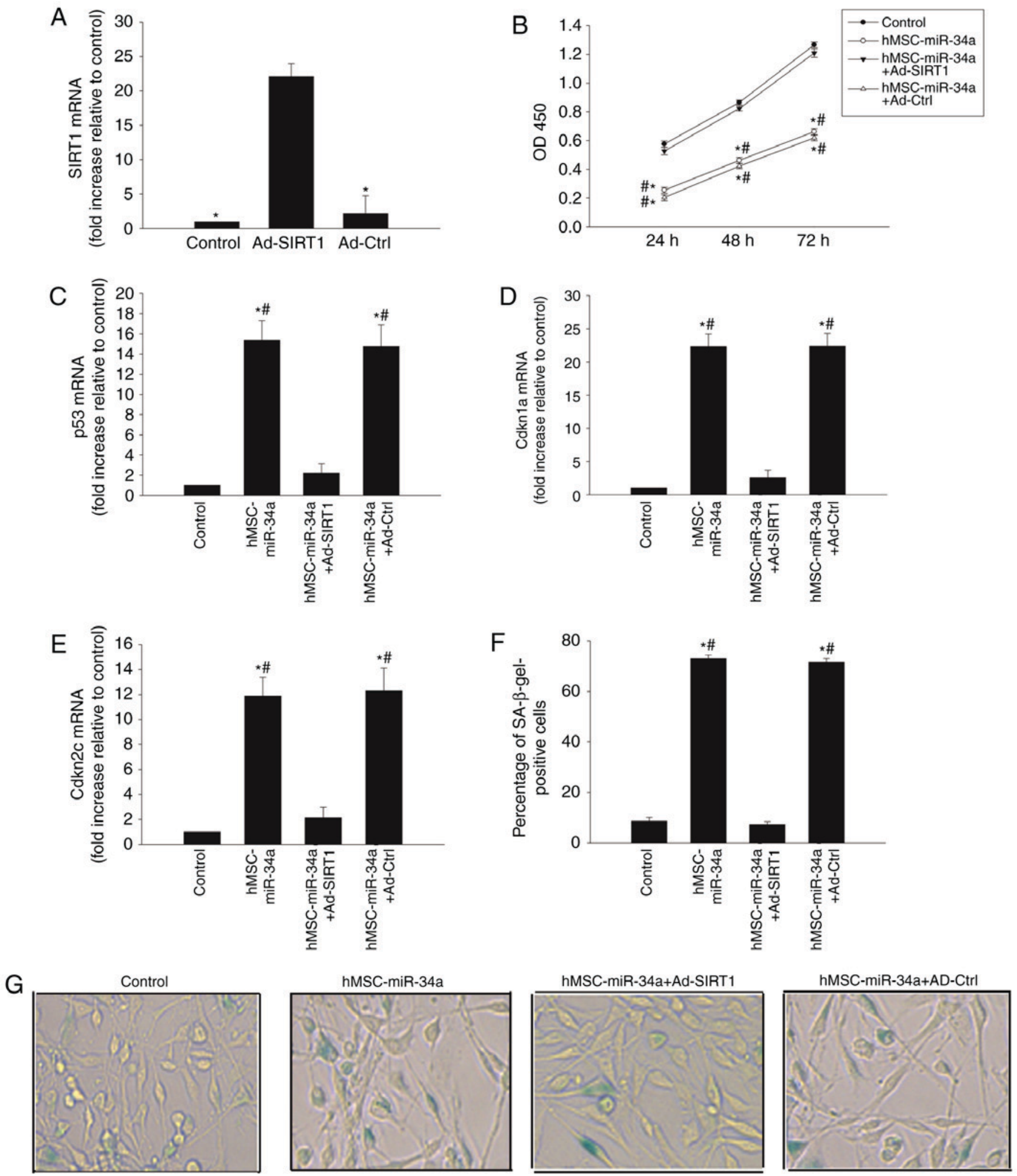

Figure 3. Modulation of SIRT1 weakens the pro-senescent effects of miR-34a derived from hMSCs. (A) RT-qPCR analysis of SIRT1 mRNA levels in untransfected U87 cells and U87 cells transfected with adenoviral vectors expressing SIRT1 or a control scrambled sequence; "P<0.05 vs. Ad-SIRT1. (B) Cell proliferation was determined by the CCK-8 assay. (C) p53, (D) Cdkn1a, and (E) Cdkn2c mRNA levels were analyzed by RT-qPCR. (F) The percentage of $\beta$-gal positive cells. (G) Representative images of the SA- $\beta$-gal staining. Data represents mean \pm standard deviation from three independent experiments; ${ }^{*} \mathrm{P}<0.05$ vs. Control; "P<0.05 vs. hMSC-miR-34a+Ad-SIRT1. hMSCs, human mesenchymal stem cells; $\beta$-gal, $\beta$-galactosidase; SA, senescence-associated; RT-qPCR, reverse transcription-quantitative polymerase chain reaction.

overexpress SIRT1 in U87 cells, and it was identified that the pro-senescent effect induced by miR-34a delivered by hMSCs, was completely reversed by SIRT1 overexpression.
DNA damage is a network of signaling pathways that is able to induce cellular impairment in glioma (11). The activation of DNA damage also modulates senescence-related cellular 

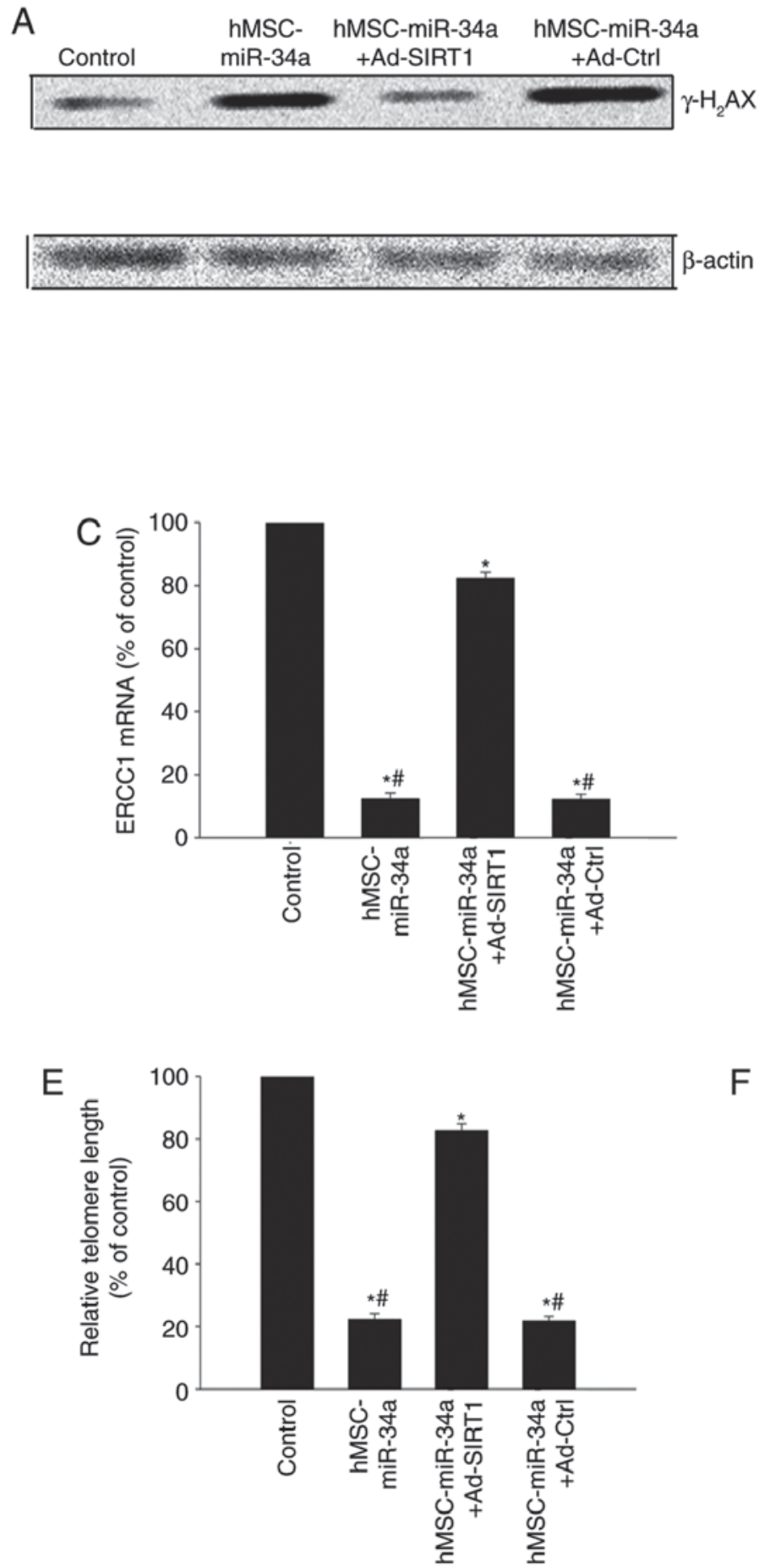
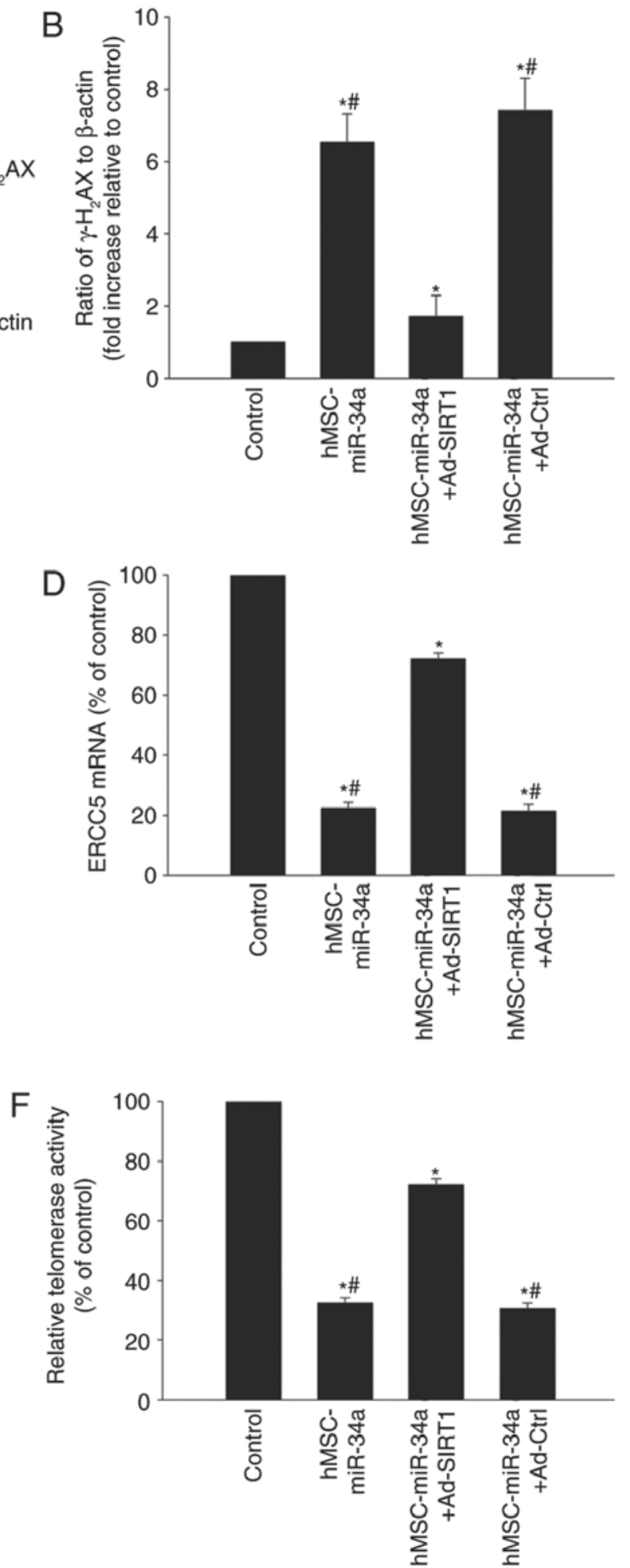

Figure 4. hMSC-derived miR-34a triggered the DNA-damage response and impaired telomere. U87 cells, transfected with adenoviral vectors expressing SIRT1 or a control scrambled sequence, were co-cultured with hMSCs overexpressing miR-34a. In parallel experiment, untransfected U87 cells were co-cultured with hMSCs overexpressing miR-34a and untreated U87 cells were used as a control. (A) Image and (B) quantification of western blotting of $\gamma-\mathrm{H}_{2} \mathrm{AX}$ protein expression levels. (C) ERCC1, (D) ERCC5, and (E) telomere length mRNA levels were analyzed by reverse transcription-quantitative polymerase chain reaction. (F) Telomerase activity was measured by a Telo TAGGG telomerase PCR ELISA PLUS kit. Data represents mean \pm standard deviation from three independent experiments; "P<0.05 vs. Control; " $\mathrm{P}<0.05$ vs. hMSC-miR-34a+Ad-SIRT1. hMSCs, human mesenchymal stem cells; miR, microRNAs; $\mathrm{H}_{2} \mathrm{AX}$, $\mathrm{H} 2 \mathrm{~A}$ histone family, member $\mathrm{X}$.

processes, including cell cycle checkpoint regulation and programmed cell death (33). DNA damage induces cell cycle arrest to provoke cellular senescence (34). The present study identified that inducing DNA damage was accompanied with glioma cell senescence, and $\gamma-\mathrm{H}_{2} \mathrm{AX}$ expression increased. A previous study reported that miR-34a impaired cardiac contractile function during ageing, by inducing DNA damage responses and telomere attrition (35). A previous study also 
showed that transient introduction of miR-34a into HCC cell lines inhibited telomere length, which induced senescence-like phenotypes and affected cellular viability (36). In agreement with previous results, the present study revealed that miR-34a delivered by hMSCs induced DNA damage, shortened telomere length, and impaired telomerase activity, resulting in cellular senescence.

In conclusion, the results of the present study indicated that miR-34a delivered by MSCs induced glioma U87 cell senescence by directly inhibiting SIRT1, resulting in increased DNA damage, suggesting that hMSCs delivered miR-34a may serve as a novel therapeutic target in glioma.

\section{Acknowledgements}

Not applicable.

\section{Funding}

The present study was supported by the Zhejiang Provincial Natural Science Foundation of China (grant no. LQ17C060002), the Medical Scientific Research foundation of Zhejiang Province of China (grant no. WKJ-ZJ-1525) and the Wenzhou Science and Technology Bureau Foundation (grant no. Y20170085).

\section{Availability of data and materials}

The datasets used and/or analyzed during the current study are available from the corresponding author on reasonable request.

\section{Authors' contributions}

QL and CDW made substantial contributions to the acquisition of data. LC, JLL and ZZZ analyzed and interpreted the data. CYW was involved in data analysis and drafting the manuscript. ZPS and XHL were involved in the conception and design of the study, and revised it critically for important intellectual content.

\section{Ethics approval and consent to participate}

Not applicable.

\section{Patient consent for publication}

Not applicable.

\section{Competing interests}

The authors declare that they have no competing interests.

\section{References}

1. Osuka S and Van Meir EG: Overcoming therapeutic resistance in glioblastoma: The way forward. J Clin Invest 127: 415-426, 2017.

2. Hingtgen S, Figueiredo JL, Farrar C, Duebgen M, Martinez-Quintanilla J, Bhere D and Shah K: Real-time multi-modality imaging of glioblastoma tumor resection and recurrence. J Neurooncol 111: 153-161, 2013.
3. Stupp R, Mason WP, van den Bent MJ, Weller M, Fisher B, Taphoorn MJ, Belanger K, Brandes AA, Marosi C, Bogdahn U, et al: Radiotherapy plus concomitant and adjuvant temozolomide for glioblastoma. N Engl J Med 352: 987-996, 2005.

4. Sharif S, Ghahremani MH and Soleimani M: Delivery of exogenous miR-124 to glioblastoma multiform cells by Wharton's Jelly mesenchymal stem cells decreases cell proliferation and migration, and confers chemosensitivity. Stem Cell Rev 14: 236-246, 2018.

5. Mangraviti A, Tzeng SY, Gullotti D, Kozielski KL, Kim JE, Seng M, Abbadi S, Schiapparelli P, Sarabia-Estrada R, Vescovi A, et al: Non-virally engineered human adipose mesenchymal stem cells produce BMP4, target brain tumors, and extend survival. Biomaterials 100: 53-66, 2016

6. Bartel DP: MicroRNAs: Genomics, biogenesis, mechanism, and function. Cell 116: 281-297, 2004.

7. Okada N, Lin CP, Ribeiro MC, Biton A, Lai G, He X, Bu P, Vogel H, Jablons DM, Keller AC, et al: A positive feedback between $\mathrm{p} 53$ and miR-34 miRNAs mediates tumor suppression. Genes Dev 28: 438-450, 2014.

8. Adams BD, Wali VB, Cheng CJ, Inukai S, Booth CJ, Agarwal S, Rimm DL, Győrffy B, Santarpia L, Pusztai L, et al: miR-34a silences c-SRC to attenuate tumor growth in triple-negative breast cancer. Cancer Res 76: 927-939, 2016.

9. Lang FM, Hossain A, Gumin J, Momin EN, Shimizu Y, Ledbetter D, Shahar T, Yamashita S, Parker Kerrigan B, Fueyo J, et al: Mesenchymal stem cells as natural biofactories for exosomes carrying miR-124a in the treatment of gliomas. Neuro Oncol 20: 380-390, 2018

10. Squatrito M, Brennan CW, Helmy K, Huse JT, Petrini JH and Holland EC: Loss of ATM/Chk2/p53 pathway components accelerates tumor development and contributes to radiation resistance in gliomas. Cancer Cell 18: 619-629, 2010.

11. Bao S, Wu Q, McLendon RE, Hao Y, Shi Q, Hjelmeland AB, Dewhirst MW, Bigner DD and Rich JN: Glioma stem cells promote radioresistance by preferential activation of the DNA damage response. Nature 444: 756-760, 2006.

12. Li L, Yuan L, Luo J, Gao J, Guo J and Xie X: MiR-34a inhibits proliferation and migration of breast cancer through down-regulation of Bcl-2 and SIRT1. Clin Exp Med 13: 109-117, 2013.

13. Livak KJ and Schmittgen TD: Analysis of relative gene expression data using real-time quantitative PCR and the 2(-Delta Delta $\mathrm{C}(\mathrm{T})$ ) method. Methods 25: 402-408, 2001.

14. Filippi-Chiela EC, Bueno e Silva MM, Thomé MP and Lenz G: Single-cell analysis challenges the connection between autophagy and senescence induced by DNA damage. Autophagy 11: 1099-1113, 2015.

15. Crepin T, Carron C, Roubiou C, Gaugler B, Gaiffe E, Simula-Faivre D, Ferrand C, Tiberghien P, Chalopin JM, Moulin B, et al: ATG-induced accelerated immune senescence: Clinical implications in renal transplant recipients. Am J Transplant 15: 1028-1038, 2015.

16. Cawthon RM: Telomere measurement by quantitative PCR. Nucleic Acids Res 30: e47, 2002.

17. Rupaimoole R and Slack FJ: MicroRNA therapeutics: Towards a new era for the management of cancer and other diseases. Nat Rev Drug Discov 16: 203-222, 2017.

18. Di Micco R: Sensing the breaks: Cytosolic chromatin in senescence and cancer. Trends Mol Med 23: 1067-1070, 2017.

19. Louis DN, Perry A, Reifenberger G, von Deimling A, Figarella-Branger D, Cavenee WK, Ohgaki H, Wiestler OD, Kleihues P and Ellison DW: The 2016 world health organization classification of tumors of the central nervous system: A summary. Acta Neuropathol 131: 803-820, 2016.

20. Dolecek TA, Propp JM, Stroup NE and Kruchko C: CBTRUS statistical report: Primary brain and central nervous system tumors diagnosed in the United States in 2005-2009. Neuro Oncol 14 (Suppl 5): v1-v49, 2012.

21. Furnari FB, Fenton T, Bachoo RM, Mukasa A, Stommel JM, Stegh A, Hahn WC, Ligon KL, Louis DN, Brennan C, et al: Malignant astrocytic glioma: Genetics, biology, and paths to treatment. Genes Dev 21: 2683-2710, 2007.

22. Huang T, Kim CK, Alvarez AA, Pangeni RP, Wan X, Song X, Shi T, Yang Y, Sastry N, Horbinski CM, et al: MST4 phosphorylation of ATG4B regulates autophagic activity, tumorigenicity, and radioresistance in glioblastoma. Cancer Cell 32: 840-855.e8, 2017.

23. Park JS, Kim IK, Han S, Park I, Kim C, Bae J, Oh SJ, Lee S, Kim JH, Woo DC, et al: Normalization of tumor vessels by Tie2 activation and Ang2 inhibition enhances drug delivery and produces a favorable tumor microenvironment. Cancer Cell 30: 953-967, 2016. 
24. Menon LG, Shi VJ and Carroll RS: Mesenchymal stromal cells as a drug delivery system. StemBook [Internet]. Harvard Stem Cell Institute, Cambridge, MA, 2008-2009.

25. Reagan MR and Kaplan DL: Concise review: Mesenchymal stem cell tumor-homing: Detection methods in disease model systems. Stem Cells 29: 920-927, 2011.

26. Liu C, Kelnar K, Liu B, Chen X, Calhoun-Davis T, Li H, Patrawala L, Yan H, Jeter C, Honorio S, et al: The microRNA miR-34a inhibits prostate cancer stem cells and metastasis by directly repressing CD44. Nat Med 17: 211-215, 2011.

27. Kim NH, Kim HS, Li XY, Lee I, Choi HS, Kang SE, Cha SY, Ryu JK, Yoon D, Fearon ER, et al: A p53/miRNA-34 axis regulates Snaill-dependent cancer cell epithelial-mesenchymal transition. J Cell Biol 195: 417-433, 2011.

28. Chang TC, Wentzel EA, Kent OA, Ramachandran K, Mullendore M, Lee KH, Feldmann G, Yamakuchi M, Ferlito M, Lowenstein CJ, et al: Transactivation of miR-34a by p53 broadly influences gene expression and promotes apoptosis. Mol Cell 26: 745-752, 2007.

29. Dong X, Jin Z, Chen Y, Xu H, Ma C, Hong X, Li Y and Zhao G: Knockdown of long non-coding RNA ANRIL inhibits proliferation, migration, and invasion but promotes apoptosis of human glioma cells by upregulation of miR-34a. J Cell Biochem 119: 2708-2718, 2018.
30. Zhang F, Cui J, Liu X, Lv B, Liu X, Xie Z and Yu B: Roles of microRNA-34a targeting SIRT1 in mesenchymal stem cells. Stem Cell Res Ther 6: 195, 2015.

31. Herskovits AZ and Guarente L: SIRT1 in neurodevelopment and brain senescence. Neuron 81: 471-483, 2014.

32. Li T, Ma J, Han X, Jia Y, Yuan H, Shui S and Guo D: MicroRNA-320 enhances radiosensitivity of glioma through down-regulation of sirtuin type 1 by directly targeting forkhead box protein M1. Transl Oncol 11: 205-212, 2018.

33. Ciccia A and Elledge SJ: The DNA damage response: Making it safe to play with knives. Mol Cell 40: 179-204, 2010.

34. Sulli G, Rommel A, Wang X, Kolar MJ, Puca F, Saghatelian A, Plikus MV, Verma IM and Panda S: Pharmacological activation of REV-ERBs is lethal in cancer and oncogene-induced senescence. Nature 553: 351-355, 2018

35. Boon RA, Iekushi K, Lechner S, Seeger T, Fischer A, Heydt S, Kaluza D, Tréguer K, Carmona G, Bonauer A, et al: MicroRNA-34a regulates cardiac ageing and function. Nature 495: 107-110, 2013.

36. Xu X, Chen W, Miao R, Zhou Y, Wang Z, Zhang L, Wan Y, Dong Y, Qu K and Liu C: miR-34a induces cellular senescence via modulation of telomerase activity in human hepatocellular carcinoma by targeting FoxM1/c-Myc pathway. Oncotarget 6: 3988-4004, 2015. 